\title{
Secondary bile acids: an underrecognized cause of colon cancer
}

\author{
Hana Ajouz, Deborah Mukherji and Ali Shamseddine*
}

\begin{abstract}
Bile acids were first proposed as carcinogens in 1939. Since then, accumulated evidence has linked exposure of cells of the gastrointestinal tract to repeated high physiologic levels of bile acids as an important risk factor for gastrointestinal cancers. High exposure to bile acids may occur in a number of settings, but most importantly, is prevalent among individuals who have a high dietary fat intake.

A rapid effect on cells of high bile acid exposure is the generation of reactive oxygen species and reactive nitrogen species, disruption of the cell membrane and mitochondria, induction of DNA damage, mutation and apoptosis, and development of reduced apoptosis capability upon chronic exposure. Here, we review the substantial evidence of the mechanism of secondary bile acids and their role in colon cancer.
\end{abstract}

\section{Introduction}

Bile Acids (BA) are normal components of the lumenal contents of the gastrointestinal (GI) tract, where they enable absorption of lipids, cholesterol, and fat-soluble vitamins. In essence, they act as a physiologic detergent and regulator of intestinal epithelial homeostasis in the gastrointestinal tract [1].

However, BAs, specifically lithocholic acid (LCA) - a secondary BA - also constitute a rare example of toxic endobiotics [2]. In fact, BAs were first proposed as a potential tumor-promoting agent in 1939 [3].

At high physiologic concentrations, BAs can cause oxidative/nitrosative stress, DNA damage, apoptosis, and mutation [4]. Furthermore, frequently repeated and prolonged exposure of tissues to high physiological levels of BAs can lead to the generation of genomic instability, development of apoptosis resistance and, ultimately, cancer [4].

And since BAs are normal components of the luminal contents of the GI tract, finding the exact mechanism of their carcinogenic effect has become intriguing. Several factors have been found to increase levels of BAs: most importantly, a high dietary fat intake.

Our aim is to explain the correlation between the concentration of fecal secondary BAs -mainly deoxycholic acid (DOC) and LCA - and the colorectal cancer incidence that

\footnotetext{
* Correspondence: as04@aub.edu.lb

Department of Hematology/Oncology, American University of Beirut Medical Center, PO Box 11-0236, Riad El Solh, Beirut 1107 2020, Lebanon
}

was highlighted by several epidemiological studies but whose molecular mechanism remain far from clear.

Furthermore, BAs were also found to be etiologic agents of other GI tract cancers, namely that of the esophagus [5], stomach [6], small intestine [7], liver [8], pancreas [9] and biliary tract [10].

\section{Review}

Biochemistry and physiology of secondary bile acids in the body

Primary BAs (cholic acid and chenodeoxycholic acid) are derived from cholesterol by a sequence of enzymatic reactions occurring mainly in the liver. Synthesis of a full complement of BAs requires 17 individual enzymes and occurs in multiple intracellular compartments that include the cytosol, endoplasmic reticulum (ER), mitochondria, and peroxisomes [11]. After synthesis, these BAs are conjugated with glycine or taurine and then excreted and stored in the gall bladder. In humans, BAs are largely re-absorbed in the terminal ileum by an active transport mechanism, but less than $5 \%$ of the BA pool enters the colon per day [12]. The BAs that enter the colon are metabolized by bacterial flora, where the primary BAs (cholic and chenodeoxycholic acid) are converted into the secondary BAs, DOC and LCA, respectively.

DOC is partly absorbed in the colon and enters the enterohepatic circulation, where it is conjugated in the liver and secreted in the bile [13]. LCA is fairly insoluble and little of it is reabsorbed [13]. Thus, the circulating 
BA pool (conjugated when it leaves the gallbladder, and then de-conjugated by action of bacterial enzymes after it enters the colon) is composed of about 30 to $40 \%$ each of cholic acid and chenodeoxycholic acid, about 20 to $30 \%$ of DOC, and less than $5 \%$ of LCA [14].

BAs are amphipathic and many of their properties are related to their amphipathic nature [15]. Their amphipathic nature enables them to get involved in emulsification and digestion of dietary fats; yet, levels above those that are physiologic are potentially membrane damaging.

\section{Factors that change secondary bile acids levels}

Almost 40 years ago, Berg was the first to make the observation that CRC (colorectal cancer) risk was higher among descendants of individuals in low-risk populations after moving to developed countries and converting to a Western-type diet that is rich in red meat and saturated fatty acids [16]. This was also consistent with a prospective cohort study that investigated 55,487 Danish middle-aged men and women and suggested that adherence to recommendations for five lifestyle factors (physical activity, smoking, waist circumference, alcohol intake and diet) may indeed considerably reduce CRC risk [17].

Prolonged, high consumption of red meat and saturated fatty acids were found to increase CRC risk. In their case control study, Bayerdorffer et al. [18] confirmed that DOC (Doxycholic acid) levels were significantly higher in the sera of patients with colorectal adenomas. Later, Bayerdorffer et al. [19] found that this positive association between DCA in the serum and colorectal adenomas was highest in the unconjugated fraction, which originates directly from the colon. High fat diets stimulate bile discharge, hence they increase the concentration of BAs above physiologic levels [20]. Population-based studies have shown that subjects who consume high-fat and high-beef foods display elevated levels of fecal secondary BAs, mostly DOC and LCA, as do patients diagnosed with colonic carcinomas [12,13]. Results of such studies, however, are not very coherent due to difficulties in accurately measuring secondary BA levels in their different forms. Such incoherencies transpired because only levels of free LCA were measured, when most of LCA is in sulphated form. The increase in DOC and LCA reflects increased production of BAs in order to emulsify the increased level of dietary fat. Consequently, elevated secondary BA levels would alter the growth of intestinal epithelium, thus acting as tumor promoters [21]. Add to that, nicotine from smoking can interact synergistically in colon cells to increase oxidative stress and DNA damage [22].

Conversely, diets rich in vegetables and fruits are linked to a decreased CRC incidence. Dietary fibers (from vegetables and fruits) can bind to LCA and aid in its excretion in stool [23]; as such, fibers can protect against colon cancer. Not only fibers play a protective role, but vitamin D and high dietary Calcium supplementation also inhibits colon carcinogenesis induced by either high-fat diets or intrarectal instillation of LCA [24].

LCA activates vitamin D receptor, which may activate a feed-forward catabolic pathway that leads to the detoxification of LCA. Whereas, high dietary calcium leads to the formation of insoluble calcium soaps, this in turn decreases the concentration of free BAs in the intestinal lumen that ultimately may protect against formation of colon cancer [25].

\section{Secondary bile acids and the plasma membrane}

An essential constituent of plasma membrane is cholesterol, which rigidifies the membrane and is an important structural component of membrane microdomains [26]. Due to the fact that BAs are cholesterol derivatives with detergent properties, BAs may alter the stability of the membrane lipid bilayer [27]. In fact, BAs with increased hydrophobicity have a greater capacity to perturb the structure of, or partly digest, cell membranes [28]. Secondary BAs (DOC and LCA) also increased paracellular permeability in a dose-related manner, with LCA exerting more potent effects than DOC [29]. When present in high concentrations, secondary BAs, cause unspecific cell membrane damage resulting in focal destruction of intestinal epithelium (Payne, 2008 [4]). Worse yet, subsequent repair mechanisms involving inflammatory reactions and hyperproliferation of undifferentiated cells would then increase the risk of transition into a precancerous state. Hyperproliferation of the colorectal mucosa is regarded as an early step in colorectal tumorigenesis [30].

In the colonic epithelium, high secondary BA concentrations induce cell proliferation by activating epidermal growth factor receptors (EGFRs) and post-EGFR/ERK (extracellular signal-regulated kinase) signaling [31]. In addition, BAinduced hyperproliferation can occur through the activity of protein kinase $\mathrm{C}$ (PKC), which can be activated downstream of the EGFR or by membrane perturbations [32].

\section{Bile acids and nuclear receptors}

Nuclear receptors (NRs) are transcription factors that act as sensors of dietary and endogenous molecules, translating nutritional and hormonal stimuli into transcriptional programs [33]. Recently, it has become apparent that nuclear BA receptors FXR, vitamin D receptor (VDR) and pregnane $\mathrm{X}$ receptor (PXR)/steroid xenobiotic receptor (SXR) play an important role in protecting against carcinogenic effects of BAs by activating transcriptional programs aimed at coordinating the control of BA uptake, detoxification, and basolateral secretion [34]. FXR, a member of the nuclear receptor superfamily, responds to BAs as physiological ligands [35]. FXR has a key role in activating pathways that maintain BA homeostasis. FXR protects against intestinal tumorigenesis, possibly by a mechanism involving induction of apoptosis [36]. 
Vitamin D deficiency is a known major risk factor for colorectal cancer [37]. When vitamin D binds to VDR it functions as a transcription factor for many genes. In this manner vitamin D exerts profound antimitogenic and prodifferentiating effects on many normal and malignant cells including colon cancer cells [24]. Thus in Vitamin D insufficiency levels may not be high enough for effective regulation of cell growth and function. VDR functions as a receptor of secondary BAs such as LCA, and has a key role in activating a pathway that detoxifies LCA [37]. Similarly, the human xenobiotic receptor SXR and its rodent homolog PXR are BA receptors that when activated induce a response that detoxifies BA [38]. PXR promotes BA detoxification by activating BA metabolizing enzymes and transporters [39]. In both human colon cancer cells and normal mouse colon epithelium, PXR/SXR protects against oxidant induced apoptosis.

Interestingly, the enteric NR transcriptome has been found to be downregulated in both mouse and human models of CRC when the tissues are progressing from normal intestinal epithelia to dysplastic lesions [40]. This suggests a therapeutic and/or diagnostic potential for these transcription factors in CRC.

\section{Decreased HLA class I mRNA}

Reduced or lost expression of HLA (human leukocyte antigen) antigens is seen in human colon carcinogenesis [41]. LCA was found to reduce the expression of HLA class I antigens on the surface of colon cells by $42 \%$ [42]. This dose-dependent reduction was specific for both the target genes and the chemical structure of LCA. Not only LCA, but DOC also - though to a lesser extent - decreased steady-state HLA class I mRNA levels. Data pertinent to the in vivo status of HLA in response to LCA, however, is still lacking.

\section{Bile acids and production of reactive oxygen species and reactive nitrogen species}

One of the most important cytotoxic effects of BAs is the increased production of reactive oxygen/nitrogen species (ROS/RNS) [43]. Activation of several plasma membrane enzymes - such as NAD (P) H oxidases and phospholipase A2 - lead to the production of ROS [44]. This may also be induced by perturbations in the mitochondrial membrane. Increased production of ROS/RNS, can lead to increased DNA damage and thus, increased mutation. The production of ROS/RNS following BA exposure is likely to occur through multiple pathways involving disruptions of the cell membrane and mitochondria [43].

\section{Bile acids and NF-kB activation}

The balance between whether BAs induce proliferation or cell death in colonic epithelial cells is finely tuned by activation of NF-kB. The ability of BAs to induce activation of
NF-kB largely determines intestinal epithelium cell fate [45]. Closely related to the BA's ability to induce ROS production and inflammation, the redox-sensitive transcription factor NF-kB is also important in many cellular processes such as inflammation and apoptosis [4]. Persistent activation of this factor (NF-kB) in the colon results in colitis and ultimately colon cancer [46]. ROS dependent and independent pathways can activate NF$\mathrm{kB}$ thus meticulously regulating the balance between cell proliferation and demise.

A report has highlighted the mechanism of DOCinduced NF-kB activation in HCT116 cells by showing the significant correlation that binds NAD (P) H oxidase, $\mathrm{Na}+/ \mathrm{K}+-\mathrm{ATPase}$, cytochrome $\mathrm{P} 450$ isoform 1B1, calcium levels and the terminal mitochondrial respiratory complex IV [47].

\section{Secondary bile acids and DNA damage}

BAs induce DNA damage in colon cells with oxidative DNA damage being a likely component [48]. Defective repair of oxidative DNA damage is linked to increased risk of colon cancer. ROS causes oxidative damage in DNA by disrupting the base excision repair pathway.

Genetic instabilities and chromosomal alterations are frequently found in CRC [49]. BAs can induce genomic instability in colonic epithelial cells through multiple mechanisms, including the disruption of mitosis (leading to aneuploidy), defects in spindle assembly checkpoints, oxidative DNA damage, cell cycle arrest at G1 and/or G2 along with improper alignment of chromosomes at the metaphase plate and multipolar divisions [50]. The numerous studies showing that BAs induce DNA damage in colon cells suggest that BAs may also induce mutation and genomic instability. DOC may induce K-ras mutations as well as aneuploidy and micronuclei formation [51].

\section{Secondary bile acids and cell death}

BAs have the potential to induce cell death both through nonspecific detergent effects and receptor-mediated interactions [52]. Elevated DOC and LCA levels promote apoptosis primarily through activation of the intrinsic apoptotic pathway involving stimulation of mitochondrial oxidative stress, generation of reactive oxygen species (ROS), cytochrome $\mathrm{C}$ (cytC) release and activation of cytosolic caspases [53]. Yui et al. recently reported a biphasic effect of cytoprotection and induction of apoptosis by hydrophobic BAs in the HCT116 cell line [54], with induction of different cellular responses depending on BA concentrations. This has raised a probability that epithelial cells of the intestinal tract acquire resistance to apoptosis after chronic exposure to low concentrations of hydrophobic BAs [34]. In a physiological condition, epithelial cells are exposed to proapoptotic stimuli, causing DNA damage or oxidative stress, some of which act as tumor initiators. Apoptosis that occurs 
spontaneously in vivo prevents tumor incidence by eliminating damaged cells [55]. Several studies of colon cancer patients have shown that epithelial cells in areas of the colonic mucosa that do not contain the cancer itself have increased resistance to induction of apoptosis by DOC [56]. In addition, the expression of anti-apoptotic protein $\mathrm{Bcl}-\mathrm{xL}$ is elevated in the colorectal mucosa adjacent to colorectal adenocarcinomas [57].

\section{Conclusions}

Since the CRC incidence and mortality rates are expected to increase in the coming decades, in-depth understanding of the molecular and cellular mechanisms underlying $\mathrm{CRC}$ becomes crucial. Focusing on the role of secondary BAs in developing CRC would be of great significance since altering the risks that increase secondary BAs would alter the incidence of CRC. Not only that, but secondary BAs may become an effective screening marker. Secondary bile acids solve the puzzle of colorectal cancer because they sit at the crossroad of nutritional and hormonal signals modulating the tangled interactions between the environmental factors, such as diet, and the nuclear receptors such as VDR. The pivotal question that emerges from the current evidence is to specify what epigenetic abnormalities are required in the crypt stem cell to render them prone to secondary BA. The next challenge is to unravel how potential stem cell specific mutations render them more prone to environmental factors, which in turn, renders them more prone toward either normal or tumorigenic phenotypes.

\section{Abbreviations}

BA: bile acids; CRC: colorectal cancer; DOC: deoxycholic acid; EGFRs: epidermal growth factor receptors; ER: endoplasmic reticulum ERK, extracellular signal-regulated kinase; Gl: gastrointestinal; LCA: lithocholic acid; NR: nuclear receptors; PKC: protein kinase C; PXR: pregnane $X$ receptor; RNS: reactive nitrogen species; ROS: reactive oxygen species; SXR: steroid xenobiotic receptor; VDR: vitamin D receptor.

\section{Competing interests}

The authors declare that they have no competing interests.

\section{Authors' contributions}

HA drafted the manuscript, AS and DM participated in the design and coordination of the study. All authors read and approved the final manuscript.

Received: 6 August 2013 Accepted: 9 May 2014

Published: 24 May 2014

\section{References}

1. Fiorucci S, Cipriani S, Mencarelli A, Renga B, Distrutti E, Baldelli F: Counterregulatory role of bile acid activated receptors in immunity and inflammation. Curr Mol Med 2010, 10:579-595.

2. Hofmann AF: Detoxification of lithocholic acid, a toxic bile acid: relevance to drug hepatotoxicity. Drug Metab Rev 2004, 36:703-722.

3. Cook JW, Kennaway EL, Kennaway NM: Production of tumors in mice by deoxycholic acid. Nature 1940, 145:627.

4. Payne CM, Bernstein C, Dvorak K, Bernstein H: Hydrophobic bile acids, genomic instability, Darwinian selection, and colon carcinogenesis. Clin Exp Gastroenterol 2008, 1:19-47.
5. Dvorak K, Payne CM, Chavarria M, Ramsey L, Dvorakova B, Bernstein H, Holubec H, Sampliner RE, Guy N, Condon A, Bernstein C, Green SB, Prasad A, Garewal HS: Bile acids in combination with low $\mathrm{pH}$ induce oxidative stress and oxidative DNA damage: relevance to the pathogenesis of Barrett's oesophagus. Gut 2007, 56:763-771.

6. Dixon MFMN, Neville PM, Moayyedi P, Axon AT: Bile reflux gastritis and intestinal metaplasia at the cardia. Gut 2002, 51:351-355.

7. Ross RK, Hartnett NM, Bernstein L, Henderson BE: Epidemiology of adenocarcinomas of the small intestine: is bile a small bowel carcinogen? Br J Cancer 1991, 63:143-145.

8. Ohtaki YHT, Hiramatsu K, Kanitani M, Ohshima T, Nomura M, Wakita H, Aburada M, Miyamoto Kl: Deoxycholic acid as an endogenous risk factor for hepatocarcinogenesis and effects of gomisin A, a lignan component of Schizandra fruits. Anticancer Res 1996, 16:751-755.

9. Adachi TTY, Kuroki T, Mishima T, Kitasato A, Fukuda K, Tsutsumi R, Kanematsu T: Bile-reflux into the pancreatic ducts is associated with the development of intraductal papillary carcinoma in hamsters. J Surg Res 2006, 136:106-111.

10. Komichi D, Tazuma S, Nishioka T, Hyogo H, Chayama K: Glycochenodeoxycholate plays a carcinogenic role in immortalized mouse cholangiocytes via oxidative DNA damage. Free Radic Biol Med 2005, 39:1418-1427.

11. Björkhem I, Eggertsen G: Genes involved in initial steps of bile acid synthesis. Curr Opin Lipidol 2001, 12:97-103.

12. Nagengast FM, Grubben MJ, van Munster IP: Role of bile acids in colorectal carcinogenesis. Eur J Cancer 1995, 31A:1067-1070.

13. Hofmann AF, Cravetto C, Molino G, Belforte G, Bona B: Simulation of the metabolism and enterohepatic circulation of endogenous deoxycholic acid in humans using a physiologic pharmacokinetic model for bile acid metabolism. Gastroenterology 1987, 93:693-709.

14. Hofmann AF: The Continuing Importance of Bile Acids in Liver and Intestinal Disease. Arch Intern Med 1999, 159:2647-2658.

15. Hofmann AF, Rods AA: Physicochemical properties of bile acids and their relationship to biological properties: an overview of the problem. J Lipid Res 1984, 25:1477-1489.

16. Berg A: Nutrition, development, and population growth. Popul Bull 1973, 29:3-37.

17. Kirkegaard $\mathrm{H}$, Johnsen NF, Christensen J: Association of adherence to lifestyle recommendations and risk of colorectal cancer: a prospective Danish cohort study. BMJ 2010, 341:c5504.

18. Bayerdörffer E, Mannes GA, Richter WO, Ochsenkühn T, Wiebecke B, Köpcke W, Paumgartner G: Increased serum deoxycholic acid levels in men with colorectal adenomas. Gastroenterology 1993, 104:145-151.

19. Bayerdörffer E, Mannes GA, Ochsenkühn T, Dirschedl P, Wiebecke B, Paumgartner G: Unconjugated secondary bile acids in the serum of patients with colorectal adenomas. Gut 1995, 36:268-273.

20. Behar J: Physiology and Pathophysiology of the Biliary Tract: The Gallbladder and Sphincter of Oddi. Rev ISRN Physio/ 2013, 2013: Article ID 837630.

21. Pai R, Tarnawski AS, Tran T: Deoxycholic Acid Activates -Catenin Signaling Pathway and Increases Colon Cell Cancer Growth and Invasiveness. Mol Biol Cell 2004, 15:2156-2163.

22. Crowley-Weber CL, Dvorakova K, Crowley C, Bernstein H, Bernstein C, Garewal H, Payne CM: Nicotine increases oxidative stress, activates NFkappaB and GRP78, induces apoptosis and sensitizes cells to genotoxic/ xenobiotic stresses by a multiple stress inducer, deoxycholate: relevance to colon carcinogenesis. Chem Biol Interact 2003, 145:53-66.

23. Jenkins D, Wolever TM, Rao AV, Hegele RA, Mitchell SJ, Ransom TP, Boctor DL, Spadafora PJ, Jenkins AL, Mehling C, Relle LK, Connelly PW, Story JA, Furumoto EJ, Corey P, Wursch P: Effect on blood lipids of very high intakes of fiber in diets low in saturated fat and cholesterol. N Engl J Med 1993, 329:21-26.

24. Newmark HL, Yang K, Kurihara N, Fan K, Augenlicht LH, Lipkin M: Westernstyle diet-induced colonic tumors and their modulation by calcium and vitamin D in C57BI/6 mice: a preclinical model for human sporadic colon cancer. Carcinogenesis 2009, 30:88-92.

25. Lorenzen JK, Nielsen S, Holst JJ, Tetens I, Rehfeld JF, Astrup A: Effect of dairy calcium or supplementary calcium intake on postprandial fat metabolism, appetite, and subsequent energy intake. Am J Clin Nutr 2007, 85:678-687.

26. Jean-Louis S, Akare S, Ali MA, Mash EA Jr, Meuillet E, Martinez JD: Deoxycholic Acid Induces Intracellular Signaling through Membrane Perturbations. J Biol Chem 2006, 281:14948-14960. 
27. Chen X, Resh MD: Cholesterol Depletion from the Plasma Membrane Triggers Ligand-independent Activation of the Epidermal Growth Factor Receptor. J Biol Chem 2002, 227:49631-49637.

28. Sagawa H, Tazuma S, Kajiyama G: Protection against hydrophobic bile salt-induced cell membrane damage by liposomes and hydrophilic bile salts. Am J Physiology 1993, 264:G835-G839.

29. Stenman LK, Holma R, Korpela R: High-fat-induced intestinal permeability dysfunction associated with altered fecal bile acids. World J Gastroenterol 2012, 18:923-929.

30. Ochsenkühn T, Bayerdörffer E, Meining A, Schinkel M, Thiede C, Nüssler V, Sackmann M, Hatz R, Neubauer A, Paumgartner G: Colonic mucosal proliferation is related to serum deoxycholic acid levels. Cancer 2000, 85:1664-1669.

31. Hylemon PB, Zhou H, Dent P: Bile acids as regulatory molecules. J Lipid Res 2009, 50:1509-1520.

32. Rao YP, Stravitz RT, Vlahcevic ZR, Gurley EC, Sando JJ, Hylemon PB: Activation of protein kinase $C$ alpha and delta by bile acids: correlation with bile acid structure and diacylglycerol formation. J Lipid Res 1997, 38:2446-2454

33. D'Errico I, Moschetta A: Nuclear receptors, intestinal architecture and colon cancer: an intriguing link. Cell Mol Life Sci 2008, 65:1523-1543.

34. Bernstein H, Bernstein C, Payne CM, Dvorak K: Bile acids as endogenous etiologic agents in gastrointestinal cancer. World J Gastroenterol 2009, 15:3329-3340.

35. Chen WD, Wang YD, Meng Z, Zhang L, Huang W: Nuclear bile acid receptor FXR in the hepatic regeneration. Biochim Biophys Acta 2011, 1812:888-892.

36. Maran RR, Thomas A, Roth M, Sheng Z, Esterly N, Pinson D, Gao X, Zhang Y, Ganapathy V, Gonzalez FJ, Guo GL: Farnesoid X receptor deficiency in mice leads to increased intestinal epithelial cell proliferation and tumor development. J Pharmacol Exp The 2009, 328:469-477.

37. Makishima M, Lu TT, Xie W, Whitfield GK, Domoto H, Evans RM, Haussler MR, Mangelsdorf DJ: Vitamin $D$ receptor as an intestinal bile acid sensor. Science 2002, 296:1313-1316.

38. Zhang B, Xie W, Krasowski MD: PXR: a xenobiotic receptor of diverse function implicated in pharmacogenetics. Pharmacogenomics 2008, 9:1695-1709.

39. Staudinger JL, Goodwin B, Jones SA, Hawkins-Brown D, MacKenzie Kl, LaTour A, Liu Y, Klaassen CD, Brown KK, Reinhard J, Willson TM, Koller BH, Kliewer SA: The nuclear receptor PXR is a lithocholic acid sensor that protects against liver toxicity. Proc Natl Acad Sci U S A 2001, 98:3369-3374.

40. Modica S, Murzilli S, Salvatore L, Schmidt DR, Moschetta A: Nuclear bile acid receptor FXR protects against intestinal tumorigenesis. Res Cancer 2008, 68:9589-9594.

41. Tsioulias G, Godwin TA, Goldstein MF, McDougall CJ, Ngoi SS, DeCosse J, Rigas B: Loss of colonic HLA antigens in familial adenomatous polyposis. Cancer Res 1992, 52:3449-3452.

42. Arvind P, Papavassiliou ED, Tsioulias GJ, Duceman BW, Lovelace Cl, Geng W, Staiano-Coico L, Rigas B: Lithocholic acid inhibits the expression of HLA class I genes in colon adenocarcinoma cells. Differential effect on HLA-A, -B and -C loci. Mol Immunol 1994, 31:607-614.

43. Bernstein H, Bernstein C, Payne CM, Dvorakova K, Garewal H: Bile acids as carcinogens in human gastrointestinal cancers. Mutat Res 2005, 589:47-65.

44. Reinehr R, Becker S, Eberle A, Grether-Beck S, Haussinger D: Involvement of NADPH oxidase isoforms and Src family kinases in CD95-dependent hepatocyte apoptosis. J Biol Chem 2005, 280:27179-27194.

45. Strauch ED, Bass BL, Rao JN, Vann JA, Wang JY: NF-kappaB regulates intestinal epithelial cell and bile salt-induced migration after injury. Ann Surg 2003, 237:494-501.

46. Karin M: NF-kappaB as a critical link between inflammation and cancer. Cold Spring Harb Perspect Biol 2009, 1:a000141.

47. Glinghammar B, Inoue H, Rafter JJ: Deoxycholic acid causes DNA damage in colonic cells with subsequent induction of caspases, COX-2 promoter activity and the transcription factors NF-kB and AP-1. Oxford J 2002, 23:839-845.

48. Powolny A, Xu J, Loo G: Deoxycholate induces DNA damage and apoptosis in human colon epithelial cells expressing either mutant or wild-type p53. Int J Biochem Cell Biol 2001, 33:193-203.

49. Armaghany T, Wilson JD, Chu Q, Mills G: Genetic Alterations in Colorectal Cancer. Gastrointest Cancer Res 2012, 5:19-27.

50. Degirolamo C, Modica S: Palasciano G Bile acids and colon cancer: Solving the puzzle with nuclear receptors. Trends Mol Med 2011, 17:564-572.
51. Narahara H, Tatsuta M, lishi H, Baba M, Uedo N, Sakai N, Yano H, Ishiguro S: $\mathrm{K}$-ras point mutation is associated with enhancement by deoxycholic acid of colon carcinogenesis induced by azoxymethane, but not with its attenuation by all-trans-retinoic acid. Int J Cancer 2000, 88:157-161.

52. Bernstein $H$, Holubec $H$, Warneke JA, Garewal H, Earnest DL, Payne CM, Roe DJ, Cui $\mathrm{H}$, Jacobson EL, Bernstein C: Patchy field defects of apoptosis resistance and dedifferentiation in flat mucosa of colon resections from colon cancer patients. Ann Surg Oncol 2002, 9:505-517.

53. Perez MJ, Briz O: Bile-acid-induced cell injury and protection. World J Gastroenterol 2009, 15:1677-1689.

54. Yui S, Kanamoto R, Saeki T: Biphasic regulation of cell death and survival by hydrophobic bile acids in HCT116 cells. Nutr Cancer 2009, 61:374-380.

55. Lowe SW, Lin AW: Apoptosis in cancer. Oxford J 1999, 21:485-495.

56. Yui S, Kanamoto R, Saeki T: Deoxycholic acid can induce apoptosis in the human colon cancer cell line HCT116 in the absence of Bax. Nutr Cancer 2007, 60:91-96.

57. Krajewska M, Moss SF, Krajewski S, Song K, Holt PR, Reed JC: Elevated expression of $\mathrm{Bcl}-\mathrm{X}$ and reduced Bak in primary colorectal adenocarcinomas. Cancer Res 1996, 56:2422-2427.

doi:10.1186/1477-7819-12-164

Cite this article as: Ajouz et al:: Secondary bile acids: an underrecognized cause of colon cancer. World Journal of Surgical Oncology 2014 12:164.

\section{Submit your next manuscript to BioMed Central and take full advantage of:}

- Convenient online submission

- Thorough peer review

- No space constraints or color figure charges

- Immediate publication on acceptance

- Inclusion in PubMed, CAS, Scopus and Google Scholar

- Research which is freely available for redistribution

Submit your manuscript at www.biomedcentral.com/submit
C BioMed Central 